\title{
Más allá del humo. La ecología política de los incendios forestales a partir del caso de Horta de Sant Joan (Tarragona, Cataluña)
}

\author{
Marien González Hidalgo \\ Iago Otero Armengol \\ Giorgos Kallis
}

Universitat Autònoma de Barcelona. Institut de Ciència i Tecnologia Ambientals marien.gonzalezhidalgo@gmail.com iago.otero@uab.cat giorgoskallis@gmail.com

Recepción: enero de 2012 Aceptación: mayo de 2012

\section{Resumen}

Analizamos el dramático incendio de Horta de Sant Joan de 2009 en Cataluña, bajo el marco de la ecología política. La historia ambiental local, los cambios de usos del paisaje forestal anterior al incendio y el choque entre los diferentes discursos sociales alrededor de éste revelan diferentes formas sociopolíticas de construir la relación entre la naturaleza y la sociedad. Cada actor social explica y evalúa la gestión del territorio y del incendio mediante escalas de tiempo e intereses diferentes. Estos distintos discursos se pueden clasificar según el grado en que favorecen la inclusión o la exclusión del fuego en el sistema socioecológico. Nuestro análisis muestra los diferentes "paisajes deseados" propuestos por los actores sociales, cuya contextualización y análisis permiten realizar una reflexión más profunda sobre los valores dominantes y dominados en relación con los bosques y los incendios. Concluimos que es necesaria una adecuada politización del debate en torno a las causas de los incendios forestales y las formas en las que la sociedad catalana responde a ellos.

Palabras clave: incendio forestal; construcción social; paisajes deseados; lo político.

Resum. Més enllà del fum. L'ecologia política dels incendis forestals a partir del cas d'Horta de Sant Joan (Tarragona, Catalunya)

Analitzem el dramàtic incendi d'Horta de Sant Joan de 2009 a Catalunya en el marc de l'ecologia política. La història ambiental local, els canvis d'usos del paisatge forestal anterior a l'incendi i el xoc entre els diferents discursos socials al voltant d'aquest ens parlen de diferents formes sociopolítiques de construir la relació entre natura i societat. Cada actor social explica i avalua la gestió del territori i de l'incendi d'acord amb escales temporals i interessos diferents. Els diversos discursos es poden classificar segons el grau d'inclusió o exclusió del foc en el sistema socioecològic. La nostra anàlisi mostra els "paisatges desitjats» de cada actor social, la contextualització i l'anàlisi dels quals permeten realitzar una reflexió més profunda sobre els valors dominants i dominats en relació amb els boscos i els 
incendis. Concloem que és necessària una politització adequada del debat sobre les causes dels incendis forestals i les respostes que la societat catalana hi dóna.

Paraules clau: incendi forestal; construcció social; paisatges desitjats; allò polític.

Résumé. Au-delà de la fumée: l'ecologie politique des incendies forestiers. Le cas d'étude d'Horta de Sant Joan (Tarragone, Catalogne)

Nous analysons le dramatique incendie de Horta de Sant Joan en 2009 en Catalogne, dans le cadre de l'écologie politique. L'histoire locale de l'environnement, les changements dans le paysage forestier utilisé avant l'incendie et l'affrontement entre différents discours sociaux autour du feu, réalisent différentes façons socio-politiques de construire la relation société-nature. Chaque acteur social, explique et évalue la gestion des terres et du feu selon différentes échelles de temps et intérêts. Ces différents discours peuvent être classés en fonction de la mesure qui favorisent l'inclusion ou l'exclusion du feu dans le système socio-écologique. Notre analyse met en lumière les différents "paysages souhaités» proposé par les acteurs sociaux, dont la contextualisation et l'analyse de permettre une réflexion plus profonde sur les valeurs dominantes et dominées par rapport aux forêts et aux incendies. Nous concluons qu'il doit y avoir politisation appropriée autour les causes et les réponses des feux de forêt en Catalogne.

Mots clé: feu de forêt; construction sociale; paysages souhaités; la politique.

Abstract. Seeing beyond the smoke: the political ecology of wildfires through the case of Horta de Sant Joan (Tarragona, Catalonia)

This paper analyses the tragic 2009 wildfire of Horta de Sant Joan in Catalonia. The local environmental history, the changes in land use of the pre-fire forest landscape, and the clash between different social discourses after the wildfire reveal different sociopolitical forms of constructing the relationship between nature and society. Each social actor explains wildfire and forest management according to different time scales and interests. These discourses can be classified by the degree of inclusion or exclusion of fire in the social-ecological system. The contextualisation and analysis of the «desired landscapes» proposed by the social actors allows for a deeper reflection on contested understandings and values in relation to forests and wildfires. We conclude by arguing in favour of a proper re-politicisation of the debate around the causes of and the responses to wildfires.

Keywords: forest fire; social construction; desired landscapes; the political.

\section{Sumario}

Introducción Los discursos más allá del humo

La construcción social Consideraciones finales

de los incendios forestales

Agradecimientos

Metodología y área de estudio

Referencias bibliográficas

Breve historia ambiental 


\section{Introducción}

El incendio forestal de Horta de Sant Joan, en adelante Orta ${ }^{1}$, ya forma parte de la memoria colectiva de todas las personas que vivieron en Cataluña, especialmente desde julio de 2009 (cuando se produjo el incendio) hasta la salida vencedora del partido catalán CiU en las elecciones autonómicas de noviembre de 2010. Ya en marzo de 2010, la prensa informaba que el 52\% de la ciudadanía catalana pedía dimisiones de cargos políticos por la gestión del incendio de Orta (La Vanguardia, 12 de marzo de 2010). No fue el área quemada, mucho menor que la de otros incendios estivales en Cataluña, sino la muerte de los cinco bomberos del GRAF (Grup d'Actuacions Forestals) lo que propulsó este incendio hacia un escenario mediático y político con pocos precedentes. Pero la historia del incendio de Orta no comienza cuando dos jóvenes, por causas desconocidas, inician un fuego la tarde del 20 de julio de 2009, sino que forma parte de un proceso más amplio y multiescalar de cambios en las relaciones que la sociedad establece con el fuego y los bosques y, por tanto, con la naturaleza.

Los ecosistemas mediterráneos tienen una larga historia de humanización y los fuegos son y han sido parte de los mismos (Pyne, 1997). Pero la tendencia al aumento de los grandes incendios forestales ${ }^{2}$ (GIF) comienza a preocupar debido a sus riesgos e impactos, lo cual motiva grandes inversiones y campañas públicas para evitarlos. Al igual que Tsing (2005: IX) describe los bosques indonesios como resultado de "proyectos socioculturales complejos fruto de colaboraciones e interconexiones en redes deslocalizadas", los incendios en el Mediterráneo responden a complejas y diversas causas en las que se entremezclan escalas individuales, locales, regionales e internacionales. Debido a su complejidad, las formas de valoración sobre la capacidad o la incapacidad de gestión de los incendios forestales pueden variar mucho según provengan de las poblaciones afectadas por los mismos, de los gestores políticos o de las organizaciones regionales e internacionales.

El objetivo de este artículo es analizar las construcciones sociales que subyacen en los discursos sobre los incendios bajo el marco teórico de la ecología política (Peet y Watts, 2004). En el análisis y la gestión de los incendios, la perspectiva puramente ecológica o de dinámicas forestales es la más habitual, y normalmente las cuestiones sociales aparecen agrupadas como "económicas», «de estilos de vida» o "culturales». Nuestra intención aquí es hacer énfasis en «lo político», entendido como el antagonismo irreductible en cualquier

1. Orta, nombre original de origen íbero de Horta de Sant Joan, cuya etimología indica «punto alto». Por considerar que provenía de hort ('huerto') se le añadió la letra $h$ a mediados del siglo XIX. En 1914, el Ayuntamiento añadió «de Sant Joan» para diferenciar el nombre de la población del del barrio barcelonés de Horta (Carbó, 2007: 15).

2. El plan INFOCAT (plan especial de emergencias para incendios forestales de la Generalitat de Cataluña, revisión de 2011) define el Gran Incendio Forestal (GIF) como aquel que mantiene de forma sostenida una velocidad, una intensidad y una longitud de llama que superan la capacidad del sistema de extinción o que afecta a más de 500 hectáreas. Así mismo, también se consideran grandes incendios forestales aquellos que pueden afectar a la población peligrosamente y de forma importante. 
sociedad a la hora de plantearse futuros alternativos, nuevas formas de organización y distribuciones del poder (Mouffe, 2007). Esto nos aleja de la ecología apolítica, que tiende a atribuir los problemas ambientales a una serie de causas naturales o biofísicas más allá de la elección colectiva (Robbins, 2004; Swyngedouw, 2010). Nuestra intención es aportar una comprensión más profunda y multidisciplinar de los incendios forestales en la que se reflejen las relaciones de poder, los diferentes lenguajes de valoración que rigen el uso del territorio y las diferentes percepciones de las causas y los impactos de los incendios (Pyne, 2001). Por tanto, nuestra pregunta central es: ¿¿Nuestra sociedad incluye o excluye a los incendios, cómo, y en base a qué intereses y a qué conocimientos? La ya comentada atención política y mediática sobre el incendio de Orta hace que, a partir de éste, se puedan estudiar con relativa facilidad los diferentes discursos que de él emergieron y que podamos analizar tanto el proceso político como las posibilidades de aprendizaje socioecológico que el incendio generó.

\section{Los usos del fuego en el mundo}

El fuego ha sido utilizado por los seres humanos desde que el Homo erectus aprendió a mantenerlo en algún lugar de África durante el Pleistoceno. En Europa, durante el Neolítico, el fuego funcionó tanto como una herramienta de autodomesticación, puesto que facilitó el paso de los humanos a formas de vida sedentarias, como de dominio sobre la naturaleza: el conocimiento y el uso del fuego era esencial en la elaboración de herramientas, en la cocción de alimentos y en la realización de rozas para caza y ganadería (Pyne, 1997). El fuego incorporó también significados sagrados y/o simbólicos: además del papel central del fuego en la construcción del «hogar» ${ }^{3}$, los mitos y leyendas, los ritos y sacrificios en torno al mismo han sido y son fuente de variados estudios históricos y antropológicos. Sin embargo, no es necesario ir tan lejos en el tiempo y en el espacio para encontrar usos estratégicos del fuego por parte de grupos o sociedades indígenas y/o rurales como herramienta para la gestión agrosilvopastoril ${ }^{4}$. El pastoreo, la agricultura itinerante (o de roza y quema), el control de plagas o la prevención de nuevos incendios, entre otras, son prácticas que se benefician de los incendios y que se mantienen hoy en día en diversas comunidades rurales e indígenas, especialmente en zonas de «baja densidad de población en regiones boscosas tropicales, donde [la roza y quema] presenta ventajas en comparación con los sistemas agrícolas más intensivos» (Lauk y Erb, 2009: 307). Sin embargo, a escala mundial, la tendencia hacia la mecanización, la industrialización y la expansión del uso de combustibles

3. La palabra hogar se refiere al sitio donde se enciende fuego (generalmente con leña) en una casa, alrededor del cual, ya desde las épocas griega y romana, se comía y se oraba, y al cual se ofrendaban flores, frutas, incienso, vino, etc. (Fustel de Coulanges, 1987).

4. Manejo de los recursos propio de las economías campesinas, con usos de la tierra múltiples e integrados, especialmente agrícolas, ganaderos y forestales. 
fósiles en la agricultura se ha traducido en la creación de una agroindustria en la que el uso del fuego, como tantas otras prácticas de gestión tradicional (como las dedicadas a la reposición de la fertilidad de los suelos), deja de tener sentido (Altieri, 2002).

Este cambio en los hábitos de uso del fuego no debe entenderse simplemente como una cuestión técnica, sino que está intensamente definido por fuerzas sociopolíticas que dan forma a determinadas relaciones entre la naturaleza y la sociedad. El miedo y las percepciones negativas del fuego proceden de una idea europea, basada en la rentabilidad económica de la madera de los bosques centroeuropeos (Kull, 2004; Xantopolous, 2004), así como en las limitaciones territoriales en cuanto a áreas boscosas (Lewis, 1989; Lauk y Erb, 2009). Estas formas de conocimiento que conceptualizan al fuego como «malo» se fortalecen con la generalización del paradigma de la ingeniería forestal en el siglo XIX, cuando el fuego es relegado a ocupar definitivamente el papel de "destructivo» (Seijo, 2009a), con lo cual se impone una forma concreta de utilización de los recursos forestales. Diferentes autores han estudiado conflictos entre visiones conservacionistas y/o urbanas que conceptualizan el fuego como «malo», y la visión de los cazadores recolectores, pastores y agricultores de roza y quema, que lo consideran como «bueno», por ser agente regenerador de sus recursos: conocimientos colonizadores versus locales en Madagascar (Kull, 2004), guardaparques versus grupos indígenas en Venezuela (Lewis, 1989) y población blanca versus población negra en Sudáfrica (Kepe, 2005). A pesar del conocimiento concreto de estos grupos sobre cómo, cuándo y dónde usar el fuego, Lewis (1989) argumenta que una mirada de superioridad sobre el conocimiento indígena o tradicional, a través de formas de poder y control, se traduce en un régimen concreto de fuegos. Así, se construye un único "conocimiento verdadero" que se materializa en políticas que favorecen el control o la prohibición del uso del fuego "para recrear un bosque imaginario, deseado» (Sletto, 2008).

El conocimiento local preciso y los simbolismos socioculturales que rodean el uso del fuego hacen que, a menudo, el mantenimiento de este fuego «bueno» suponga tanto una herramienta de gestión de los recursos naturales, como una forma de resistencia. Tal es el caso del «incendiarismo rural» como forma de protesta (Kuhlken, 1999) compartido por realidades tan diferentes como Madagascar (Kull, 2004) y Galicia (Seijo, 2005). En ambos conflictos, se expresa una batalla ideológica sobre la soberanía del paisaje: en relación con la imposición de medidas conservacionistas en el primer caso, y frente a los cambios en los derechos de propiedad y uso del monte común en el segundo. El uso simultáneamente práctico y simbólico del fuego dentro de la comunidad, junto con características como el anonimato y la autopropagación parecen facilitar el mantenimiento de estas prácticas campesinas de resistencia. Esta atención a la conformación histórica, económica y política del sistema socioecológico (SSE) es fundamental en cualquier análisis de los incendios forestales.

Como vemos, los incendios forestales pueden ser muy distintos, no sólo en las formas en que se inician y/o se propagan, sino también en las formas en que 
son analizados. Todas estas formas comparten, sin embargo, una naturaleza política: reflejan cómo y quién organiza los SSE y qué conocimientos ecológicos, sociales y políticos emergen en torno a los incendios forestales en los discursos políticos y mediáticos. Así mismo, reflejan cuáles de ellos prevalecen frente a otros y, por tanto, cuáles se constituyen como políticas dominantes en el uso de los recursos naturales.

\section{Los fuegos en el Mediterráneo}

El fuego ha formado parte de los SSE del Mediterráneo a lo largo de su historia. Por un lado, los incendios son parte de un régimen de perturbaciones naturales, puesto que las condiciones climáticas (patrones de humedad, temperatura, tormentas, viento) han determinado la presencia de fuego desde hace milenios (Pausas et al., 2008). Por otro lado, el fuego ha sido utilizado activamente como un instrumento de gestión agrosilvopastoril (Pyne, 1997). Esta presencia histórica se refleja en las culturas mediterráneas, donde el fuego aparece como un elemento cultural y simbólico: las hogueras del solsticio de verano son expresiones de esta socialización del fuego, en torno a la celebración de rituales por el buen tiempo, el culto a la fertilidad (entre otras, de la tierra) y la protección del sol contra las enfermedades (González y Buxó, 1997). Así mismo, la fiesta de las fallas de Valencia es una muestra de la sociabilidad festiva que se hila en rutinas y organizaciones colectivas en torno al hecho de «quemar para que otras cosas puedan crecer desde las cenizas» (Costa, 2002: 497).

Esta presencia inmanente y ubicua de fuegos e incendios en el Mediterráneo da lugar a que el fuego pueda ser considerado como uno de los principales gestores del paisaje (Naveh, 1975). En el Mediterráneo, la tendencia a sequías extremas con cierta frecuencia puede haber ayudado a seleccionar caracteres que también han sido útiles para la respuesta al fuego, de tal forma que las plantas han evolucionado y han sido seleccionadas para soportar determinadas combinaciones ígneas de intensidad y frecuencia (Terradas, 2001). Esto hace que muchas rebroten después de un incendio, como es el caso de especies de Quercus como la encina (Q. ilex) y la coscoja (Q. coccifera), y otras germinen, por ejemplo el pino carrasco (Pinus halepensis) (Terradas, 1996). Así mismo, algunas especies animales, como algunos taxones de gasterópodos terrestres (Santos et al., 2009) y aves (Arrizabalaga y Llimona en Terradas, 1996) muestran también dinámicas positivas en la regeneración postincendio.

Pese a esta resiliencia ${ }^{5}$ de los SSE mediterráneos y a la identificación de beneficios por parte de pastores y agricultores después de un fuego (Molinero et al., 2008), los incendios forestales son predominantemente considerados factores de fuerte degradación, incluso más que otras «alteraciones humanas tales como el desmonte, la tala, el sobrepastoreo y la urbanización» (Pausas et

5. La resiliencia es la capacidad de un sistema socioecológico para absorber perturbaciones, manteniendo procesos y estructuras esenciales (Adger et al., 2005). 
al., 2008: 719). Con fuerte influencia de los paradigmas de la fitosociología y la biología de la conservación, los incendios siguen siendo considerados retrasadores de la sucesión ecológica, aunque la ecología de las perturbaciones ha sido aceptada lentamente (Seijo, 2009b). Las dificultades de recuperación, junto con los impactos en el suelo y la hidrología (Terradas, 1996), así como la reciente preocupación sobre las emisiones atmosféricas (Lauk y Erb, 2009), son los impactos negativos que más suelen destacarse de los incendios forestales.

Sin embargo, a la hora de evaluar la capacidad de recuperación postincendio, se han de considerar características del fuego tales como la recurrencia, la intensidad, la superficie quemada y el estado original del ecosistema. Por ejemplo, aunque los incendios pequeños tienden a aumentar la fertilidad del suelo y la heterogeneidad del paisaje (Pausas y Lloret, 2007), por lo general, los GIF tienden a reducir ambas. Incluso la capacidad de germinación del popularmente conocido como "pino pirófito" (pino carrasco, $P$. halepensis) puede verse afectada por una alta recurrencia de fuegos (Díaz-Delgado et al., 2002), y la autosucesión ${ }^{6}$ del pino negral ( $P$. nigra) y del pino rojo ( $P$. sylvestris) puede verse obstaculizada durante los primeros años después de grandes incendios de copas (Rodrigo et al., 2004). Estos factores, junto con el actual régimen de GIF que explicaremos más adelante, alertan de que actualmente los procesos de resiliencia ecológica postincendio por sí solos no son suficientes para una correcta gestión forestal.

\section{Cataluña arde}

Cataluña, situada en el noreste de la península Ibérica, comparte con los territorios de la cuenca mediterránea la presencia histórica de incendios en sus SSE. Alimentados tanto por el uso tradicional del fuego en los sistemas agrosilvopastoriles como por las características bioclimáticas, los incendios suelen ser más frecuentes durante períodos de calor, debido al estrés hídrico de la vegetación por las sequías de verano. Aunque no disponemos de datos que nos permitan conocer el régimen de incendios anterior a los cambios socioeconómicos que mencionamos más adelante, las personas ancianas de las zonas de montaña litoral y prelitoral nos permiten intuir un régimen de incendios diferente al actual (véase, por ejemplo, Badia et al., 2010), con eventos de poca intensidad que eran controlados mediante herramientas manuales o ramas por la población local.

Los cambios socioeconómicos que ha vivido Cataluña después de la década de 1960 (Saurí y Boada, 2006) han tenido importantes consecuencias en las zonas rurales y de montaña, como el éxodo rural (Bayona y Gil, 2010), el abandono de los usos agrosilvopastoriles (Tàbara et al., 2003) y el descenso de la población activa dedicada al sector primario. El desarrollo capitalista en

6. La autosucesión es la capacidad de determinadas comunidades vegetales de recuperar rápidamente el mismo pool de especies que existían con anterioridad a la perturbación (Rodrigo et al., 2004). 
España, como en otros países, supuso la concentración espacial de las actividades económicas (Collantes, 2001), pero, a su vez, los valores urbanos se expandieron sobre las realidades rurales (Saurí y Boada, 2006; Otero, 2010). Estos cambios complejos provocan que la pasada «convivencia con los incendios forestales» (comentada en el párrafo anterior) se haya ido perdiendo junto a la cultura de uso y dependencia de los recursos forestales, lo cual ha dado paso a un régimen dominado por los GIF (Castellnou et al., 2007). Unos pocos grandes incendios son responsables de una elevada proporción de la superficie total quemada $(0,4 \%$ de los incendios forestales son responsables de cerca del $77 \%$ de la superficie total quemada en el período 1992-2009, véase la tabla 1). El manejo actual de las áreas forestales se caracteriza mayoritariamente por bosques que tienden a no gestionarse, fomentando sus usos recreativos

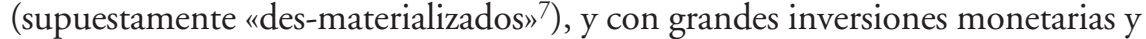
técnicas para la supresión de los incendios. La erosión del uso agrosilvopastoril del paisaje se traduce en un crecimiento incontrolado de la superficie forestal, que aumentó en un 5,18\% en el período 1993-2005, a expensas de las tierras agrarias (CREAF, 2005). En 2006, más del 60\% del territorio catalán correspondía a áreas forestales ${ }^{8}$, la mayoría de ellas con densidades elevadas de árboles de clases diametrales bajas. En ausencia de la práctica de la entresaca, esta situación conlleva procesos de autoaclareo con elevada mortalidad de árboles y acumulación de madera muerta y, por tanto, combustible disponible. Alrededor del $75 \%$ de las áreas forestales en Cataluña están asociadas a fuegos que se propagan fácilmente y cuya intensidad depende de la cantidad de material disponible para quemarse (CREAF, 2005).

Tabla 1. Número de incendios y área afectada en Cataluña según tamaño de los mismos. Períodos 1982-1991 y 1992-2009. Datos del Departament d'Agricultura, Ramaderia, Pesca, Alimentació i Medi Natural de la Generalitat de Catalunya, disponibles en www.gencat.cat

\begin{tabular}{|c|c|c|c|c|c|c|c|c|}
\hline \multirow[b]{2}{*}{$\begin{array}{l}\text { Tamaño } \\
\text { del incendio }\end{array}$} & \multicolumn{4}{|c|}{$1982-1991$} & \multicolumn{4}{|c|}{ 1992-2009 } \\
\hline & $\begin{array}{c}\text { Número } \\
\text { de incendios }\end{array}$ & $\%$ & $\begin{array}{c}\text { Área } \\
\text { afectada (ha) }\end{array}$ & $\%$ & $\begin{array}{c}\text { Número } \\
\text { de incendios }\end{array}$ & $\%$ & $\begin{array}{c}\text { Área } \\
\text { afectada (ha) }\end{array}$ & $\%$ \\
\hline $0-1$ ha & 2.747 & 47,8 & 714 & 0,5 & 10.051 & 79,4 & 1.578 & 1 \\
\hline $1-10$ ha & 2.332 & 40,5 & 6.432 & 4,4 & 2.123 & 16,8 & 5.608 & 3,6 \\
\hline $10-100$ ha & 522 & 9,1 & 14.666 & 10 & 353 & 2,8 & 10.307 & 6,6 \\
\hline $100-500$ ha & 104 & 1,8 & 20.080 & 15 & 83 & 0,7 & 19.112 & 12,3 \\
\hline$>500$ ha & 47 & 0,8 & 103.422 & 70,2 & 46 & 0,4 & 119.067 & 76,5 \\
\hline
\end{tabular}

7. Usamos esta expresión en relación con la ilusión de que una economía con menos industria y más servicios es menos intensiva en términos de energía y recursos materiales (MartínezAlier, 2009).

8. Las áreas forestales incluyen las siguientes categorías de cubierta del suelo (CREAF, 2005): bosque denso, bosque aclarado, matorrales, pastos y tierras naturalmente improductivas, como roquedos. 
En 1986, 65.800 hectáreas ardieron en Cataluña, 19.850 de las cuales lo hicieron en los alrededores y en la propia montaña de Montserrat (esa montaña «esencial», como la describen Nogué y Vicente, 2004). La gran superficie quemada y la visibilidad desde la realidad urbana de Barcelona supusieron un punto de inflexión en los planteamientos sobre las formas de abordar la gestión forestal y los incendios. El Gobierno catalán reaccionó estableciendo el programa Foc Verd ('Fuego Verde'), centrado en la detección rápida de los incendios y en la eficacia de los medios de extinción. Así mismo, se buscaba fomentar la organización de propietarios de terrenos forestales a nivel local en las llamadas «agrupaciones de defensa forestal» (ADFs), puesto que el 80\% de los bosques catalanes son de propiedad privada (Minguell y Àngel, 2009). Pero los GIF de 1994 y 1998 truncaron la sensación de que los incendios eran controlables de esta manera. Agua, medios humanos y aéreos no eran suficientes para hacer frente a los incendios de alta intensidad. Por ello, con la intención de recuperar la confianza de la población, y percatándose de la necesidad de una mejor comprensión del fuego, en 1999 el Departament d'Interior de la Generalitat de Catalunya creó el Grup de Recolzament d'Actuacions Forestals (GRAF), como unidad especial dentro del cuerpo de bomberos especializada en la lucha contra los grandes incendios. El GRAF retoma la sabiduría histórica de pastores y campesinado para la mejora de pastos mediante el uso y el conocimiento de las dinámicas del fuego y la adapta como herramienta de prevención de incendios y de manejo de los mismos.

Sin embargo, el proceso de reaprendizaje hacia el reconocimiento del papel del fuego en la dinámica del SSE está lejos de completarse. Aunque algunos trabajos escuchan los valores y las percepciones de las comunidades afectadas por los incendios forestales (véase, a modo de ejemplo, Plana et al., 2002), el análisis del incendio como parte de la dinámica social aún requiere de más y mejor atención. Muy al contrario, son otras las circunstancias que suelen ocupar la atención política o mediática en el análisis de las causas de los incendios forestales, especialmente después de episodios catastróficos, puesto que éstas actúan como "chivos expiatorios» de un problema cuya solución a menudo puede requerir cambios políticos fundamentales en el uso de la tierra (Badia et al., 2002). Nos disponemos a analizar de cerca los discursos alrededor de los incendios para así entender cómo se construyen y qué hay «más allá del humo», es decir, detrás de ellos.

\section{La construcción social de los incendios forestales}

\section{La culpa}

Según el Ministerio de Medio Ambiente (2006), del total de incendios del periodo 1996-2005 (que quemaron más de 1.200.000 hectáreas forestales y no forestales), el $60 \%$ fueron provocados, mientras que el $17 \%$ se debieron a negligencias u otras causas. Mientras que los primeros son más habituales en la zona nororiental de la península Ibérica, en Cataluña son más frecuentes los 
causados por negligencias (41\% de los incendios del período 1994-2009). De éstos, el $13 \%$ están relacionados con quemas agrí́colas ${ }^{9}$ mal gestionadas y casi un $2 \%$ con la quema de pastizales ${ }^{10}$. Estas cifras responden al abandono de los usos agrosilvopastoriles, que conllevan la pérdida del conocimiento en el uso del fuego y el envejecimiento de las personas usuarias del mismo (de forma similar a lo que Molinero et al., 2008, exponen para la región de Castilla y León), así como el aumento de la combustibilidad del paisaje.

Los gobiernos y algunas asociaciones ecologistas han desarrollado diversas legislaciones y campañas públicas con el propósito de desalentar el uso del fuego, exigir mayor vigilancia, limitación en su uso y mayores penas judiciales, tanto a excursionistas (Seijo, 2009b) como a pirómanos, especuladores y campesinos. La necesidad de encontrar un "Otro incendiario» (Davis, 1998), como «el agricultor irresponsable» o "el ganadero inconsciente» (Greenpeace, 2007: 15), coincide con las teorías de psicología social que apuntan a la necesidad, después de un episodio catastrófico, de encontrar una responsabilidad, preferentemente humana (Kumagai et al., 2006). De esta manera, parece que cualquier uso del fuego es criminalizado, mientras que queda oculto el "papel idiosincrático del fuego en el manejo tradicional del ecosistema mediterráneo español por parte de la población rural» (Vélez, 2006, en Seijo, 2009b).

\section{Las causas naturales}

A menudo, son las condiciones climáticas las que aparecen como causas explicativas de los incendios, tanto a nivel mediático y político como académico (Piñol et al., 1998). Cuestión lógica, teniendo en cuenta que los veranos mediterráneos se caracterizan por altas temperaturas, baja humedad y frecuentes tormentas con rayos (que provocaron el 11\% de los incendios forestales del período 1994-2009 en Cataluña $\left.{ }^{11}\right)$. Además, las predicciones meteorológicas hacia condiciones más extremas, debidas al cambio climático, vaticinan nuevas dificultades para hacer frente a los incendios forestales en el futuro (Moreno, 2007).

Sin embargo, el énfasis excesivo en las circunstancias «neutrales» como las sequías, las altas temperaturas, los vientos o las características orográficas, pueden dar lugar a una despolitización de las causas y las consecuencias de los incendios. Por ejemplo, los incendios forestales de Grecia en 2007 podrían explicarse en «el marco de las condiciones climáticas extremas» o por cambios de uso del suelo fruto de una mala ordenación del territorio (Karamichas, 2007: 525). Esta tendencia a despolitizar ciertos conflictos o problemas ambientales ha sido comentada por Tsing (2005) y Swyngedouw (2010) cuando describen, respectivamente, la deforestación y el cambio climático como problemas

9. Las quemas agrícolas se realizan con el fin de eliminar restos de poda o rastrojos de cosechas y las quemas de lindes entre parcelas para evitar la colonización de matorral.

10. Estadísticas de prevención de incendios del Departament d'Agricultura, Ramaderia, Pesca, Alimentació i Medi Natural. Disponibles en www.gencat.cat.

11. Ibídem. 
reales que tienden a ser traducidos como «universales» indiscutibles. La falta de intermediación política no permite debate ni nuevos entendimientos más allá de los más convencionales, lo cual se puede aplicar también al problema de los incendios forestales, en los que la ausencia de una mirada al territorio y a la historia local hace que se escapen las cuestiones políticas.

\section{La extinción}

Como la mayoría de los países del Mediterráneo, los gobiernos de España y Cataluña destinan grandes esfuerzos a las campañas de extinción y prevención de incendios. Por ejemplo, el presupuesto de la Generalitat previsto para el verano de 2010 era de más de 30 millones de euros, con un aumento de la inversión en nuevas tecnologías, medios terrestres y aéreos respecto a años precedentes (Conseller d'Interior en la Comisión Parlamentaria de investigación sobre el incendio de Orta, reunida el 12 de marzo de 2010. Véase apartado «Metodología y área de estudio»). Debido a la fuerte repercusión social de los incendios forestales, la Administración suele responder con estas medidas «reactivas», aplicando mecanismos cada vez más complejos (medios aéreos y terrestres, nuevas tecnologías) que se pueden entender como símbolos sutiles de un sentido de omnipotencia e invulnerabilidad (Seijo, 2009b).

Sin embargo, estos esfuerzos parecen no ser útiles, puesto que, tal y como hemos visto en la tabla 1, son los incendios grandes y de alta intensidad los responsables de la mayor parte del área total quemada en Cataluña. Varios autores (Minnich, 1983; Piñol et al., 2005; González y Pukkala, 2007) cuestionan las ventajas de la extinción de incendios forestales en zonas mediterráneas en relación con la superficie quemada y con la intensidad de los mismos, entendiendo que la extinción de todo tipo de incendios (sea cual sea su tamaño) da lugar a una continuidad paisajísitca que, dada la acumulación de combustible comentada anteriormente, lleva a que se produzcan más fácilmente GIF. Esta «paradoja de la extinción» podría explicar el impacto de los GIF en Cataluña. La tolerancia cero con el uso del fuego y la extinción rápida y eficaz aumentarían la superficie quemada y la intensidad de los incendios y convertirían a los GIF en los principales factores de la gestión del paisaje (Castellnou et al., 2007). Su elevada intensidad les sitúa fuera de la capacidad de extinción.

\section{¿Fantasía verde o inclusión del fuego?}

En ciertos círculos académicos y de gestión territorial y forestal, son frecuentes los debates sobre la necesidad de incluir el fuego en la dinámica de los socioecosistemas. Entender que no se han de evitar todos los incendios forestales, sino especialmente los GIF, es un planteamiento que rompe no sólo con el paradigma de extinción de incendios, sino que además constituye un paso adelante respecto al paradigma "clásico» de prevención (Plana et al., 2005). Como se explicó anteriormente, en Cataluña se estableció una diferencia con 
la creación del GRAF en 1999 como un subcuerpo de bomberos con conocimiento del uso del fuego. Éste se concreta en el fuego técnico ${ }^{12}$ antes y durante los incendios forestales, y en la posibilidad de lucha contra incendios no en su primer perímetro, sino donde las posibilidades de extinción son más altas (lo que supone plantearse dejar quemar una parte del combustible para atacar el incendio desde otro punto de forma más segura). Las quemas prescritas son las herramientas que más reticencias suscitan en gestores, personal técnico y propietarios, lo cual supone planear en su implementación una fase de divulgación (Larrañaga et al., 2005) para poder incorporarlas con diferentes objetivos: manejo de pastos, conservación de ciertos hábitats, creación de zonas estratégicas contra GIF y medidas protectoras de zonas de interfase urbano-forestal. Todo ello con el objetivo de "no permitir incendios de alta intensidad», como un bombero del GRAF nos dijo en una de nuestras entrevistas (ver sección «Metodología y área de estudio»).

Aunque las quemas prescritas no son más caras que la extinción (Plana et al., 2005), ni causan impactos negativos sobre los suelos (Outeiro et al., 2007), y pese a la presencia histórica de los incendios en los paisajes mediterráneos, el mensaje que predomina entre la Administración y la opinión pública es que «el fuego es un enemigo a ser suprimido» (Seijo, 2009b: 106). Este paradigma de la exclusión del fuego se expresa muy claramente en el ámbito catalán. El Colegio de ingenieros forestales de Cataluña rechazó la recuperación del uso del fuego en $2006^{13}$ (Castelló, 2009) y las últimas campañas de prevención de incendios forestales han llevado títulos tan claros como Foc Zero ('Fuego Cero', en 2002) o "La millor manera d'acabar amb un incendi és no deixar que comenci» ('La mejor forma de acabar con un incendio es no dejar que empiece', en 2010). La mayoría de las asociaciones ecologistas (especialmente las más arraigadas localmente ${ }^{14}$ ) rechazan el uso del fuego técnico y proponen que las quemas agrícolas se limiten o se prohíban, por la posibilidad de desencadenar nuevos incendios forestales.

12. El fuego técnico se usa en el ámbito tanto preventivo como de extinción. En lo preventivo, toma el nombre de quemas prescritas, que se basan en la ejecución de fuego de baja intensidad de forma conducida para reducir la intensidad del incendio potencial. La utilización de quemas prescritas tiene tres objetivos principales: eliminar combustible que podría representar peligro en términos de intensidad en caso de incendio, regular la estructura de la vegetación para su explotación útil y crear una estructura de bosque óptima para extinguir posibles incendios forestales. Durante la extinción, el conocimiento de la dinámica del fuego permite propagarlo en dirección contraria al avance natural del incendio que se combate, el cual se intenta detener en la zona quemada por el contrafuego.

13. Cuando el Gobierno catalán aprobó el decreto 312/2006, de 25 de julio, que regula el uso del fuego técnico como herramienta de prevención de incendios y durante la extinción.

14. Mientras que Greenpeace, en «El futuro en llamas» (2009), propone: «Las quemas controladas o prescritas y la gestión de incendios de baja intensidad pueden ser una alternativa más a la hora de reducir la carga de biomasa forestal», las asociaciones locales tienden a posicionarse en contra de las quemas, como se evidenció cuando una asociación ecologista acusó a una quema prescrita de ser la causa del incendio de Vandellòs (Tarragona) en 2006 (GEPEC, 2007). Entendemos que esta diferencia está alimentada por el apego, la propiedad o la dependencia de las poblaciones locales con sus paisajes. 
Hay dos factores que pueden explicar el mantenimiento de este paradigma de exclusión del fuego. En primer lugar, el alto porcentaje de la propiedad privada de los bosques catalanes, especialmente en la Cataluña central, donde las grandes propiedades aún obtienen beneficios de la explotación forestal. En segundo lugar, el hecho de que el $80 \%$ de la población catalana vive en zonas urbanas, donde predomina una "visión prístina de la naturaleza», sin fuego (Saurí y Boada, 2006), a pesar de que una gran parte de esta población se encuentra en paisajes propensos a los incendios (Badia et al., 2002). Así lo muestran estudios desarrollados en zonas de interfase urbano-forestal en EEUU, cuyas comunidades locales rechazan las quemas prescritas y prefieren formas punitivas o proteccionistas más fuertes (Winter y Fried, 2000). A esto se le añade la defensa de que la sociedad debe ser capaz de prevenir los incendios forestales mediante el uso de mejores tecnologías (Kumagai et al., 2006). Se trata de lo que Stavrakakis (1997) denomina «fantasías verdes», es decir, la conceptualización de los bosques y las zonas forestales como sistemas ideales, estáticos (y por tanto incombustibles), donde la naturaleza se define como armónica, en lugar de comprender que «la naturaleza es, intrínsecamente, turbulenta, no equilibrada» (Zižek, 1991). Esta concepción tan polarizada de la naturaleza lleva a que, según el jefe del GRAF, «la extinción de los incendios forestales se haga por romanticismo" (en una de nuestras entrevistas, ver sección «Metodología y área de estudio»).

Una comprensión inclusiva de los incendios forestales en términos sociales supondría un proceso de aprendizaje de cómo responder a las incertidumbres en lo individual y lo colectivo, en los niveles sociales y políticos. Durante un incendio, además de la energía calorífica, se liberan otras «energías», tales como la participación pública (Tàbara et al., 2003), oportunidades para crecer en cohesión, la gestión de los conflictos (Carrol et al., 2005) y actos espontáneos de solidaridad (Karamichas, 2007), que pueden ser utilizadas por las comunidades afectadas para fortalecerse e incrementar su resiliencia social (Adger, 2000).

\section{Metodología y área de estudio}

Para mostrar la relevancia empírica de estos argumentos, analizamos el incendio forestal más conocido en Cataluña de los últimos años (Orta, en julio de 2009) mediante una metodología cualitativa. A pesar de que las dinámicas sociopolíticas que envuelven el incendio hacen que éste deje de ser una muestra representativa de la realidad, nuestro estudio de caso sirve como «ejemplo revelador» (Yin, 2003, en Bryman, 2008: 56), debido a la cantidad de información generada y a la introducción del mismo dentro del debate público. Esto ofrece un contexto propicio para la investigación de ciertas cuestiones por responder. En nuestro caso, ofrece material valioso para analizar las diferentes construcciones sociales de la naturaleza que emergen de las diversas interpretaciones del incendio. 
La recopilación de datos desde varias fuentes se llevó a cabo entre abril de 2010 y enero de 2011:

1. 32 entrevistas semiestructuradas a personas afectadas por el incendio $y / o$ que participan o participaron en la gestión del sistema agrosilvopastoril de Orta; activistas locales y/o ecologistas organizados localmente; personal del Parque Natural de Els Ports y de la Reserva Nacional de Caza de Tortosa y Beceite, entre otras. Las preguntas abiertas buscaban crear un espacio en el que apareciesen opiniones sobre el incendio y la gestión forestal (además de, en general, sobre la gestión del SSE), y su cambio con el tiempo: antes, durante y después del incendio de 2009. El muestreo se hizo a través del método de la bola de nieve (contacto inicial con un pequeño grupo de personas relevantes para la investigación, que después ayudan a establecer contacto con otras personas - Bryman, 2008), aprovechando las relaciones locales y garantizando así el acceso a una amplia gama de personas relacionadas con las preguntas de investigación. El material y las notas relativas a las entrevistas fueron analizadas con el fin de identificar los discursos y los "paisajes deseados" subyacentes.

2. Análisis de datos secundarios: grabaciones, actas y conclusiones de la comisión parlamentaria de investigación ${ }^{15}$, informes institucionales sobre gestión e impacto del incendio, noticias en prensa y regulaciones sobre uso del fuego y gestión de incendios (nivel local, catalán y estatal).

3. Trabajo de campo para la interpretación in situ del SSE de Orta y del macizo de Els Ports, antes (varias visitas y estancias durante los últimos diez años) y después del incendio. La mayoría de las visitas después del incendio se hicieron en compañía de alguna persona conocedora local, buscando la comprensión de la estructura y el funcionamiento del SSE, con especial atención a los usos agrosilvopastoriles y su evolución a lo largo del tiempo, así como a las estrategias de recuperación de la vegetación y las intervenciones postincendio.

4. Acercamiento al trabajo del GRAF, incluyendo varias entrevistas en la sede de Bellatera (Cerdanyola del Vallès), intercambio de conocimiento y salidas de campo para el reconocimiento in situ de la evolución de los paisajes postincendio en Cataluña durante el verano de 2010.

El municipio de Orta se encuentra en el suroeste de la provincia de Tarragona (Cataluña, ver figura 1). El pueblo actual se situa en una zona más bien plana, a 542 metros sobre el nivel del mar, rodeada al norte por la sierra de Els Pesells, un mosaico de bosques y terrenos cultivados en bancales donde ahora abundan las masías abandonadas. En la zona sur están Els Ports (zona montañosa y abrupta que forma la transición entre la Cordillera Prelitoral Catalana y el Sistema Ibérico), localmente llamado Lo Port, que, por su orografía, ha sido recurso de pastos, tanto de ganado local como de

15. Las declaraciones de la Comisión de Investigación sobre el incendio de Horta de Sant Joan fueron consultadas en www.parlament.cat/web. 
ganados trashumantes. En 2010, Orta contaba con una población total de 1.307 habitantes, cifra que representa un 5\% más que la población en 1998, pero sólo un 48\% del máximo de poblacion censado en 1897 (IDESCAT, 2010; Carbó, 2007). La baja densidad de población de Orta (alrededor de 11 habitantes por $\mathrm{km}^{2}, 119 \mathrm{~km}^{2}$ de superficie municipal) y el alto porcentaje de mano de obra dedicada a la agricultura (28\% en 2001 -IDESCAT, $2010)$, en comparación con la media catalana $(2,5 \%)$, son características que coinciden con las de su comarca, la Terra Alta, considerada la menos productora de capital (aporte al PIB de Cataluña), como ya comentaron Zografos y Martínez-Alier (2009). En la actualidad (datos de 2004, CREAF, 2005), las cubiertas del suelo de Orta se reparten así: el 46\% del municipio es bosque, principalmente denso, el 16\% es matorral, el 32\% de la superficie está dedicada a cultivos, el 1\% lo representan los prados y el 5\%, las zonas improductivas (naturales y artificiales) ${ }^{16}$.
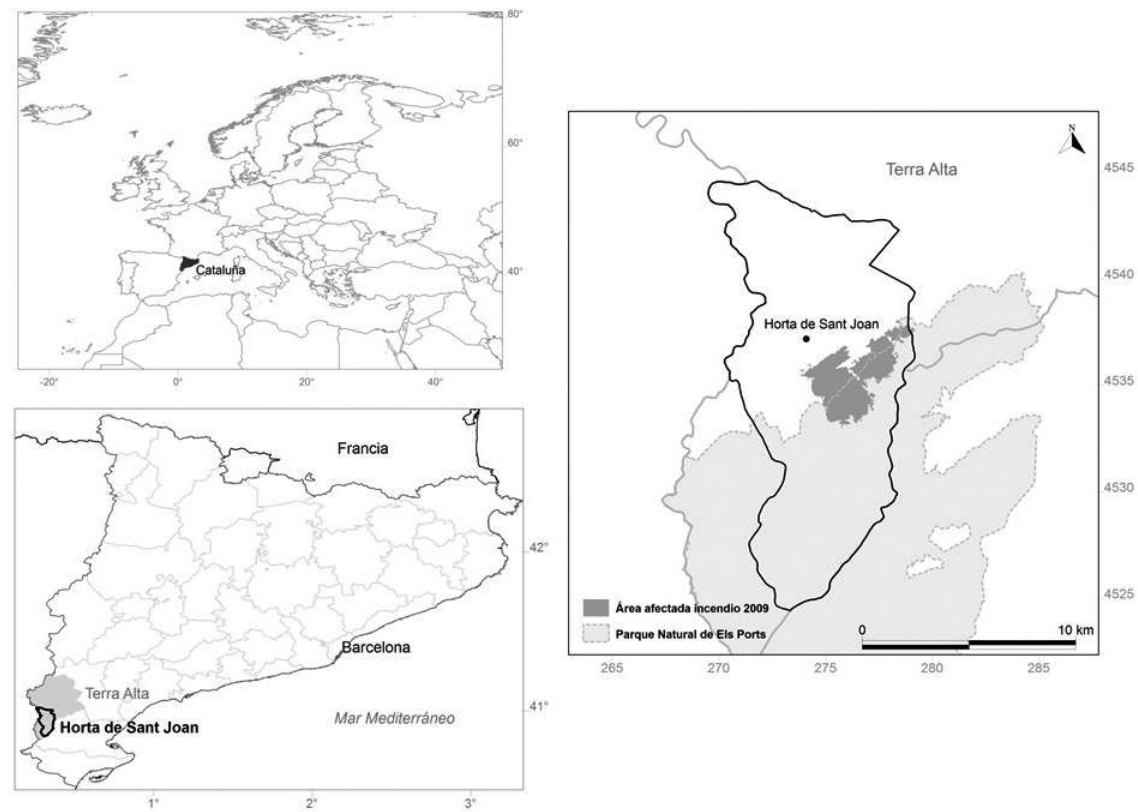

Figura 1. Ubicación del área de estudio afectada por el incendio de julio de 2009. Coordenadas en latitud-longitud y UTM (zona 31-N). Datos facilitados por GADM, Institut Cartogràfic de Catalunya y Departament d'Agricultura, Ramaderia, Pesca, Alimentació i Medi Natural. Elaboración propia con el apoyo de Marta Borrós.

16. Cubiertas del suelo por municipios (CREAF) http://www.creaf.uab.cat/iefc/pub/regions/ Comarques/CobertesTerraAlta.htm. 


\section{Breve historia ambiental}

Aunque fueron los íberos los primeros pobladores permanentes de Els Ports (siglos $\mathrm{V}$ a II aC), no existen pruebas del uso de los recursos madereros por parte de éstos, ni tampoco de los habitantes romanos y visigodos posteriores. No es hasta llegar a la época en la que la zona era parte de al-Ándalus (siglos VIII a XIII), cuando diversos textos documentan la apropiación de madera, especialmente de pino albar (Pinus sylvestris) en los bosques de Orta en el siglo X (Balanyà, 1997, en Carbó, 2007). La repoblación cristiana desde el norte del territorio catalán a través de la expansión de los dominios de la nobleza y de la Iglesia en lo que se conoce como la Cataluña Nueva se materializó a través de casas de campo familiares dispersas (masos). Este fue el caso de Els Ports, donde los asentamientos se intensificaron a partir del siglo XIII, junto con la roza y la quema (artiga en catalán) de terrenos boscosos para diponer de tierras de cultivos y obtener pastos. A pesar de su relieve abrupto y de difícil acceso, la riqueza maderera y de pastos de Orta la convertían en un lugar de interés económico, de modo que fue objeto del manejo, primero, por la Corona de Aragón (desde el siglo XII) y, más adelante, por la Armada Marina española con el fin de garantizar el suministro de madera para la construcción naval. Con las desamortizaciones del siglo XIX, la propiedad y la gestión de los recursos silvopastoriles se reestructuraron considerablemente (Carbó, 2007). El incremento de la producción agrícola (aunque con menos rendimientos por expandirse los cultivos en zonas marginales) y la explotación indirecta por medio de jornaleros fueron algunos de los cambios asociados a esta reestructuración (Vilar, 2003, tomo 5: 614).

Orta basó su economía preindustrial en la apropiación de madera, los cultivos aterrazados de vides, almendros y olivos, el pastoreo extensivo de ganado ovino y caprino, así como la explotación de los bosques para leña, carbón vegetal de diferentes especies de Quercus y resinas y breas de pino negral (Pinus nigra), enebro (Juniperus communis) y pino carrasco (Pinus halepensis). La ganadería extensiva, principlamente ovina pero también caprina (como la variedad local blanca de Rasquera), se basaba en un régimen de trastermitancia del ganado local, que en los inviernos se alimentaba en las zonas bajas y en los periodos más cálidos usaba los pastos de las tierras altas de Els Ports (conocedor local, entrevista \# 20). Por otro lado, Lo Port también era zona de paso del ganado trashumante que pasaba el invierno en las tierras bajas del Ebro y en verano se dirigía en búsqueda de pasto hacia las montañas del Maestrazgo, en la provincia de Teruel (Miralles, 2005). La disponibilidad de pastos de verano se aseguraba con quemas en primavera, hasta que, por diversas regulaciones estatales, se limita el uso de fuego, que queda relegado al control de lindes, así como a las fiestas alrededor del solsticio de verano. El uso intensivo de la producción primaria de los ecosistemas de montaña provocaba que bosques y pastizales contasen con una baja combustibilidad, por lo que el uso de este fuego raras veces se escapaba de control (antiguo colono (masover), entrevista \# 21). 
En la década de 1960, las fincas privadas de Lo Port fueron expropiadas y pasaron a ser propiedad del Ayuntamiento de Orta (propiedad que se mantiene hoy en día - Carbó, 2007). De esta forma se pretendía evitar la explotación forestal en manos de particulares mientras se realizaban grandes extracciones de pino para las vías del tren en beneficio municipal. En 1966, se declaró la Reserva de Caza de Tortosa y Beceite ${ }^{17}$, con el propósito de proteger la cabra montés (Capra pyrenaica subsp. hispanica), en consonancia con las políticas cinegéticas y conservacionistas del régimen franquista, cuyos espacios protegidos estaban pensados para las élites sociales e intelectuales (Ramos-Gorostiza, 2006), y se consideraba a la población rural como un obstáculo para la correcta gestión forestal (Seijo, 2005). Esta nueva forma de ordenación territorial y una fuerte helada en 1956 facilitaron el abandono de los masos en Els Ports, cuyas familias se mudaron al núcleo de Orta o al área de Barcelona: «[...] aunque fue para mejor, eran tiempos de miseria [...]» (antiguo colono (masover), entrevista \# 1). De forma muy interesante, esto coincide con la tesis de Siddle (2009) acerca de la «marginación de la cabra doméstica», que ya en época preindustrial se manifestaba en los imaginarios satánicos alrededor de su figura, reproductores del rechazo a la agricultura pobre y de subsistencia. Durante la industrialización, la mala imagen de la cabra se ve reforzada al subir la demanda de ganado lanar, cuando «las ovejas se constituyen como criaturas del capitalismo emergente» (Siddle, 2009: 524). Esta construcción social contrasta claramente con el «estilo de vida de ocio cinegético» que la cabra montés simboliza, con lo cual se pone de manifiesto a quién favorece el nuevo ordenamiento territorial de esta época.

Como se ha comentado anteriormente, en la segunda mitad del siglo XX, se produjeron en Cataluña fuertes cambios socioeconómicos, marcados por la introducción de los combustibles fósiles y la mercantilización del campo. En lo forestal, la disminución de la demanda de combustibles forestales supuso una reducción de los beneficios obtenidos por la explotación de los bosques. Orta comienza a distanciarse de una economía agroganadera y a acercarse a la industrial (pequeños talleres textiles en la década de 1960, construcción de dos centrales nucleares en la cercana Ascó en la década de 1970) y a la de servicios (apertura del Centro Picasso en $1991^{18}$ ). Durante este período, la superficie forestal creció de $28 \mathrm{~km}^{2}$ en 1982 a $63 \mathrm{~km}^{2}$ en 1999 (IDESCAT, 2010). Finalmente, y aunque más tarde de lo previsto debido a la falta de consenso entre los municipios y los propietarios (La Vanguardia, 8 de marzo de 1998), en 2001 se declaró el Parque Natural de Els Ports ${ }^{19}$, que ocupa un 43\% de la superficie del municipio de Orta. Hoy en día, el 36\% de la población de Orta

17. Ley 37/1966, de 31 de mayo, de reservas nacionales de caza. BOE número 131 de 2/6/1966, páginas 6900 a 6906.

18. En la primera década del siglo XX, Picasso visitó Orta dos veces. Fue su primer contacto con las rutinas rurales y sus paisajes sirvieron para comenzar a ensayar sus pinturas cubistas (Carbó, 2007).

19. Decreto 160/2001, de 12 de junio, Declaración del Parque Natural de Els Ports, que cubre más de 30.000 hectáreas y está distribuido en 11 municipios. 
se dedica a los servicios (IDESCAT, 2010). En 2008, el 80\% de la población votó en contra de la instalación de un parque eólico en un referéndum popular. Zografos y Martínez-Alier (2009) valoran este rechazo como una oportunidad para dar lugar a otros «proyectos de vida» y otras valoraciones del paisaje que mantengan y reformulicen el patrimonio natural y cultural.

En la actualidad, como en el resto de Cataluña, el uso del fuego en Orta como herramienta aparece únicamente en las quemas de restos de poda, estrictamente controladas debido al peligro de incendio que suponen ${ }^{20}$ y desalentadas por la Unión Europea en la normativa de la Política Agrícola Común ${ }^{21}$. Este hecho se suma a la sensación de burocratización de la estructura agraria, para la «obstaculización y desesperación de los pocos agricultores que quedan» (agricultor local, entrevista \# 18), mientras que otros proyectos, como «el turismo, los molinos de viento, las minas de bauxita, el parque industrial [...] no tienen tantas dificultades institucionales» (joven agricultor, entrevista \# 2). El incendio de 2009 es el quinto que Orta ha vivido en los últimos treinta años, tres de ellos como consecuencia directa de rayos ${ }^{22}$.

\section{El fuego del verano de 2009}

El Pla Alfa (programa especial de la Generalitat para la prevención de incendios forestales) anunció un riesgo de incendio entre moderado y alto para la tercera semana de julio en la comarca de la Terra Alta, debido a las altas temperaturas, la baja humedad relativa y la probabilidad de tormentas eléctricas. Del 20 al 23 de julio de 2009, un incendio provocado quemó 1.143 hectáreas: alrededor de 600 hectáreas dentro del Parque Natural de Els Ports y el 90\% de la superficie total distribuida principalmente en pequeñas propiedades privadas. Gran parte de la superficie quemada estaba cubierta por pino carrasco (Pinus halepensis), junto con pino negral ( $P$. nigra) en las zonas más altas y encinas y quejigos en el estrato arbustivo (Quercus ilex y Q. faginea). Junto con madroños (Arbutus unedo), lentiscos (Pistacia lentiscus), romeros (Rosmarinus officinalis), enebros (Juniperus communis) y coscojas (Q. coccifera), creaban «una estructura densa e impenetrable propensa a los incendios de alta intensidad $»^{23}$. Evaluado como un incendio forestal de bajo impacto ambiental a largo plazo ${ }^{24}$, el impacto fue humano: cinco bomberos del GRAF murieron durante la extinción.

20. Decreto 64/1995, del 7 de marzo, sobre las medidas de prevención de incendios forestales, que establece como obligatorio pedir un permiso para la realización de una quema agrícola. Entre el 15 marzo y el 15 octubre, la aprobación y la vigilancia dependen del Gobierno catalán central, y cualquier uso del fuego en zonas forestales está prohibido. Durante el resto del año, son las autoridades locales las responsables de autorizar su ejecución, así como las tareas de vigilancia.

21. Regulación de la Comisión Europea, núm. 796/2004, del 21 de abril de 2004.

22. Informe de l'incendi forestal de dilluns 20 de juliol de 2009 que va afectar els termes municipals d'Horta de Sant Joan i Prat de Compte, a la comarca de Terra Alta, agosto de 2009, Departament de Medi Ambient i Habitatge, Generalitat de Catalunya.

23. Informe de l'incendi forestal d'Horta de Sant Joan, julio de 2009, Departament d'Interiror, Generalitat de Catalunya.

24. Informe de l'incendi forestal de dilluns 20 de juliol de 2009..., op. cit. 
La extinción del incendio se complicó debido a un aumento de la intensidad del viento de componente suroeste (lo garbi, frecuente en la zona) durante la tarde del día 21, junto con las características orográficas del terreno. La forma en que se gestionaron las tareas de extinción fue casi de inmediato sometida a evaluación política, lo cual provocó enfrentamientos entre el Gobierno catalán y el Ayuntamiento de Orta, que se expandieron a discusiones técnicopolíticas entre $\mathrm{CiU}$ (partido que gobernaba en Orta y entonces en la oposición en el Parlament) y el Gobierno autonómico del Tripartit (que gobernó hasta noviembre de 2010). Desde el 8 de febrero hasta el 18 de marzo de 2010, tuvo lugar una comisión parlamentaria, promulgada y aprobada con el voto favorable de un tercio de los parlamentarios (de los partidos en la oposición). En ella compareció población local y cargos políticos y técnicos con un papel relevante durante la extinción o bien un cierto conocimiento del territorio. Aunque la comisión sirvió para la recopilación de mucha información técnica, formal y política sobre la gestión de la extinción del incendio, sus objetivos no fueron valorados de forma homogénea: mientras que para algunas personas se trataba de «buscar responsabilidades políticas, porque decir que todo ha sido causado por circunstancias meteorológicas o técnicas no permite mejorar la organización» (representante de CiU en la Comisión Parlamentaria celebrada el día 3 de febrero de 2010), otras consideraban que la comisión había sido creada para alimentar un «fuego político y mediático, cuyo nombre es "Elecciones 2010" " (bombero del GRAF en la Comisión Parlamentaria del día 22 de febrero de 2010).

\section{Los discursos más allá del humo}

Los actores sociales, ya sea de forma individual o en el marco de sus redes, afrontan la comprensión del fuego atendiendo a intereses, valores y conocimientos diferentes. Representamos los diferentes discursos detectados a través de nuestro caso de estudio en la figura 2a. La situación de éstos a lo largo del eje horizontal indica, de forma relativa, cuál es la escala temporal más frecuente a la hora de analizar el incendio y explicar sus visiones (es decir, no implica que sea la única utilizada por los actores). A su vez, la línea vertical separa los discursos según si éstos incluyen o excluyen la dinámica del fuego en sus propuestas de organización del SSE.

En la figura $2 \mathrm{~b}$, se simbolizan los paisajes deseados de los diferentes actores, que se expresan por medio de las diferentes propuestas de gestión con las que cada actor, o red de actores, está política y éticamente — en el sentido que sugiere Cortina (2011) - comprometido.

Obviamente, los discursos de los actores sociales no siempre permanecen tan "Concretos", ni podemos situar a cada una de las personas entrevistadas en una sola de las categorías sociales, pero usamos esta generalización para desarrollar la discusión más adelante. Agrupamos a las personas entrevistadas en cinco grupos: ecologistas (1), cargos políticos (2), agricultores y pastores (3), GRAF (4) y Parque Natural (5). A continuación, describimos 


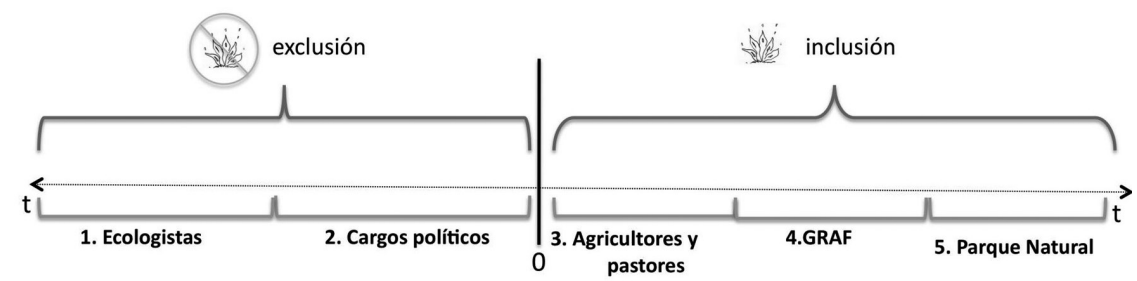

Figura 2a. Diferentes discursos según inclusión o exclusión del fuego y escala temporal del análisis.

Leyenda
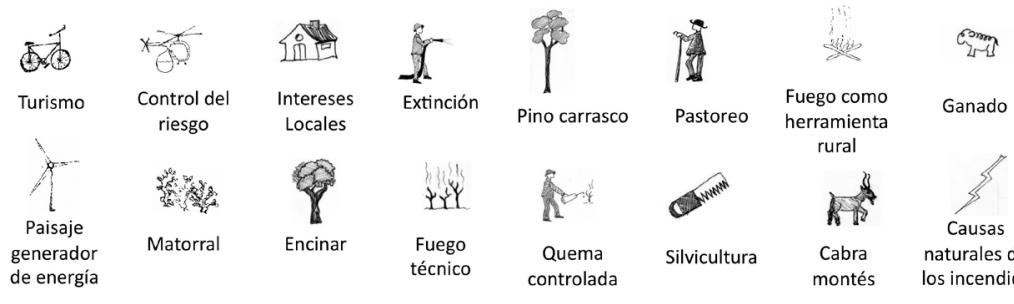

rural

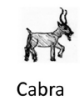

Cabra

montés
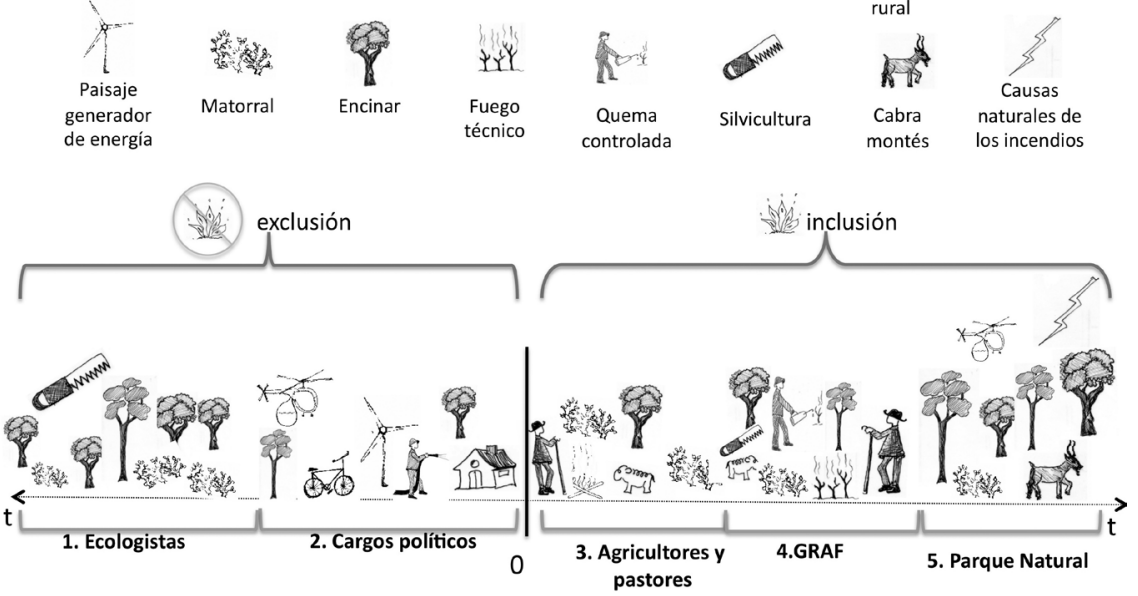

Figura 2b. Paisajes deseados de los diferentes actores sociales.

brevemente los diferentes discursos para que la discusión de los mismos sea más clara:

1. Ecologistas. Los colectivos ecologistas enfatizan las propuestas de prevención, donde la gestión forestal es la «solución de los bosques y a la crisis económica» (GEPEC, 2010). La gestión cuidadosa mediante cortas por entresaca es la herramienta central para que sea el ser humano el que, directa o indirectamente, promueva un SSE sin fuegos o con pequeños fuegos autoextinguibles.

2. Cargos politicos. Los discursos que excluyen el fuego del SSE son claros en la Comisión Parlamentaria y en diversos medios de comunicación y se centran sobre todo en la estrategia de extinción elegida para Orta. Estos discursos 
están muy influidos por las circunstancias de la muerte de los bomberos. Entran en juego intereses locales, la necesidad de controlar el riesgo por parte de la Administración catalana y las valoraciones estéticas del ecosistema (por ejemplo: turismo rural y de montaña), así como las intensamente productivas del paisaje (como la intención de implantar un parque eólico en la zona de Els Pessells).

3. Agricultores y pastores. Los discursos inclusivos del fuego aparecen a nivel local entre las personas que, en la actualidad o en el pasado, han trabajado en el sistema agrosilvopastoril. Expresiones tales como «este año las vacas tienen más para comer» (ganadero bovino, entrevista \# 8), en relación con la germinación de hierbas anuales por efecto del incendio, y «la cabra que tengo es la principal herramienta para limpiar los bosques» (ganadero de cabra local, entrevista \# 21) muestran una comprensión de las dinámicas a corto plazo temporal del incendio (antes y después del mismo), tanto en relación con la acción directa en la prevención como en sus beneficios en lo que se refiere a la regeneración de pastos.

4. GRAF. Como se ha explicado ampliamente en apartados anteriores, el GRAF propone la prevención de los GIF mediante la inclusión del fuego en el SSE, a partir del conocimiento de las prácticas de quema para la obtención de pastos. Además, el profundo conocimiento de la dinámica del fuego del GRAF proviene también de la observación de GIF in situ.

5. Parque Natural. El personal técnico del Parque Natural cuestiona la necesidad de aumentar las medidas de prevención, a la vez que muestra mucha preocupación sobre cómo gestionar la tendencia inherente al fuego de los ecosistemas, que han de conservarse a escalas temporales largas. El fuego es considerado un elemento «natural» si es causado por rayos, frente a las causas antrópicas en que los medios de extinción son considerados imprescindibles.

Las diferentes posiciones en nuestra representación de los discursos dan lugar a "fricciones». Siguiendo la metáfora que describe Tsing, éstas son puntos de choque, coincidencia y/o evolución interdiscursos o intradiscursos que son capaces de "dar lugar a nuevas modalidades de cultura y poder» (Tsing, 2005: 5). A continuación, explicamos las fricciones (1, 2 y 3 ) que aparecen en torno a la inclusión o exclusión del fuego y a las escalas temporales que los distintos grupos de actores expresan en sus discursos en torno al incendio.

\section{Fricción 1. El fuego político}

La escala de tiempo del discurso número 2 (alrededor de cuatro años, el tiempo entre elecciones) establece un escenario en el que las fuerzas políticas autonómicas versus la local, en el poder versus en la oposición, se enfrentan para analizar las circunstancias técnicas del manejo de la extinción del incendio. La discusión parlamentaria se convierte a menudo en partidista, y el discurso excluyente del fuego se acaba convirtiendo en una forma de atribuir la responsabilidad al 
«otro», como explicábamos en el apartado «La culpa». En realidad, esto resulta paradójico, puesto que estos discursos excluyentes del fuego usan el incendio forestal como medio para llegar a sus objetivos políticos. Sin embargo, aunque esta búsqueda del «culpable» podría empujar a que esta fricción fuese verdaderamente política, es decir, que diese lugar a un debate en la esfera pública que analizara proyectos hegemónicos (Mouffe, 2007), en realidad el excesivo peso partidista lo convierte en un debate despolitizado.

Esta despolitización adquiere otra faceta a nivel local, donde la teoría del rayo como iniciador del incendio, mantenida inicialmente por el Gobierno autonómico ${ }^{25}$, choca frontalmente con las voces locales que ya desde el principio afirmaban conocer "cómo y dónde se había iniciado el fuego" (ganadero ovino, entrevista \# 13). Así mismo, en lo local prevalece una sensación compartida de descoordinación en la emergencia, y que, por tanto, no cuadra con la explicación oficial del aumento de la intensidad del viento como responsable del accidente mortal. Como apuntábamos en el apartado «Las causas naturales», ambas circunstancias se traducen localmente en una incredulidad en lo que se refiere a las circunstancias naturales del incendio, que se creen construidas «para que callemos y creamos que todo lo que pasó fue sólo producto de una fatalidad», como comenta la hermana de uno de los bomberos fallecidos en el libro que publicó tras lo ocurrido con el título La veritat crema (La verdad quema) (Espinet, 2010).

El resultado de esta despolitización es que la oportunidad de entablar un debate político relacionado con la historia y la gestión de los bosques (y el fuego) en el pasado y en el presente se pierde, a la vez que se refuerza la dicotomía entre centro y periferia (es decir, Barcelona y Terra Alta). En este sentido, y en referencia al incendio y a los planes energéticos para la zona, varias de las personas locales entrevistadas nos dijeron que «nos recuerdan sólo cuándo se puede obtener un interés». Aunque la Comisión Parlamentaria terminó con 38 propuestas para la mejora de la extinción y 28 para la prevención de incendios forestales, los intereses depositados en el incendio transforman al bosque de Orta en una «expresión política de la compensación monetaria» (bombero del GRAF, entrevista \# 15). Ejemplo de ello son los trabajos forestales después del incendio ${ }^{26}$, que expresan también un paisaje deseado ( $\mathrm{n}^{\circ} 2$, figura $2 \mathrm{~b}$ ) en el

25. Al iniciarse la investigación de las causas del incendio, el Departament de Medi Ambient de la Generalitat insistió en que el causante del mismo había sido un rayo, mientras que las personas locales no estaban de acuerdo y señalaron que había sido un incendio provocado. Finalmente, la investigación policial confirmó el rumor popular y el conseller de Medi Ambient pidió disculpas por el error.

26. Existe un debate acerca de cómo se ha de gestionar un paisaje postincendio. Las teorías que son partidarias de la tala de la vegetación quemada aseguran que así se previenen las plagas y se reduce el impacto visual, mientras que la ruptura de la dinámica ecológica del sistema es uno de los argumentos en contra. En Orta, se previeron más de 2 millones de euros para los trabajos en el área quemada (Informe de l'incendi forestal de dilluns 20 de juliol de 2009 que va afectar els termes municipals d'Horta de Sant Joan i Prat de Compte, a la comarca de Terra Alta, agosto de 2009, Departament de Medi Ambient i Habitatge, Generalitat de Catalunya). 
que prima el control del riesgo y los usos no materiales y, por tanto, necesita a la naturaleza como imagen estática para que ésta pueda funcionar como «bien de consumo» (Saurí y Boada, 2006).

\section{Fricción 2. La memoria de incendios del pasado}

El incendio de Orta moviliza la memoria de la autoorganización local en la extinción de los fuegos que históricamente se han sucedido en la zona. Las personas más mayores recuerdan cómo, en el pasado, el pueblo se organizaba y cargaba agua, se hacían contrafuegos y los incendios se manejaban con facilidad. Por otro lado, los sentimientos tales como «no podemos quedarnos parados viendo cómo nuestro bosque se quema» (ganadero ovino, entrevista \# 13) son magnificados a causa del carácter privado de las parcelas afectadas, junto con el apego sentimental al paisaje.

Ambas circunstancias dan lugar a la fricción (2), que, localmente, se entiende como un conflicto de conocimiento. Personas conocedoras del territorio, antiguos pastores, bomberos locales o cazadores critican la tecnificación de la extinción del incendio («los bomberos y los altos cargos estaban mirando sólo al GPS», ex trabajadora de la fábrica textil, entrevista \# 16) y la falta de respeto al conocimiento local «si nos hubieran escuchado, los bomberos que murieron nunca hubiesen estado allí. Nadie puede entender por qué estaban allí» (varias personas entrevistadas locales). Sin embargo, la expresión puntual de este conocimiento local en un momento de emergencia contrasta con la baja actividad cotidiana de la Agrupación de Defensa Forestal, relacionada con el escaso valor monetario que las personas propietarias reciben de sus pequeñas parcelas, como nos indicaba uno de ellos (entrevista \# 7) 27 .

Como se ha visto en apartados anteriores, los cambios en el SSE de Orta son diversos y multiescalares. Los cambios en los usos del suelo y en las normativas de uso de los recursos agrosilvopastoriles, así como las crecientes restricciones en el uso del fuego, pueden haber implicado una pérdida de conocimiento ecológico local, como ha sido constatado en otras áreas del Estado español (Gómez-Baggethun et al., 2010). Es un hecho importante a tener en cuenta, puesto que la propuesta que enfatiza la ruralidad como valor en el paisaje deseado ( $\mathrm{n}^{\circ} 3$, figura $2 \mathrm{~b}$ ) choca con la Europa de la PAC, cuyas subvenciones exigen el no uso del fuego y, por tanto, el conocimiento local y actual de la dinámica del fuego no es sólo lejano en el tiempo, sino no permitido. Situar la responsabilidad del mantenimiento de este conocimiento en lo rural podría considerarse una «divinización urbana del sector rural» (bombero del GRAF, entrevista \# 15).

27. Así lo demuestra el hecho de que, en 2008, no se llevó a cabo ningún aprovechamiento forestal en toda la comarca de la Terra Alta. 


\section{Fricción 3. Fantasías verdes}

Situamos a los discursos ecologistas y del personal del Parque Natural como actores sociales que analizan el incendio de Orta introduciendo explícitamente parámetros temporales a larga escala, ya que ambos paisajes deseados son bosques maduros de Quercus ( $\mathrm{n}^{\circ} 1$ y 5 , respectivamente, en la figura $2 \mathrm{~b}$ ) que se conciben como posibles (y/o recuperables) a largo plazo. Sus argumentos «no es cierto que el sotobosque haya de estar limpio" (integrante de ONG local de conservación, entrevista \# 32), sino que «son hábitats que deben protegerse» (personal Parque Natural, entrevista \# 12), chocan con los de los actores 2 y 3 (figura 2a) del tipo «el bosque está sucio [...] es pólvora» (mayoría de los entrevistados locales) y «las llamas se apagan en invierno" (ganadero ovino, entrevista \# 4). Este conflicto podría ser entendido como el "clásico» entre población rural versus área protegida, sin embargo, el proceso de diversificación que la mayoría de los habitantes rurales ha experimentado hacia la economía de servicios termina por igualar los vocabularios rural y conservacionista, de modo que todos ellos resultan urbanos.

Sin embargo, ecologistas y personal del Parque Natural conciben de formas diferentes el papel del ser humano para incluir o excluir a los incendios del ecosistema, por tanto, es aquí donde aparece la fricción 3. Los colectivos ecologistas enfatizan las propuestas de prevención, donde la gestión forestal es la «solución de los bosques y la crisis económica» (GEPEC, 2010), mientras que el pastoreo y las quemas prescritas son rechazadas como formas de gestión, por considerarse no selectivas. Este paisaje deseado ( $\mathrm{n}^{\circ} 1$, figura $2 \mathrm{~b}$ ) concibe los incendios como destructivos, pero potencialmente autoextinguibles con una silvicultura cuidadosa, así como con medidas de control de acceso y vigilancia.

En cambio, el personal del Parque Natural cuestiona la necesidad de aumentar las medidas de prevención: «tanques de agua, cortafuegos, mantenimiento de caminos, obras forestales, y el mantenimiento puntual de algunos rebaños [...] ¿qué otra cosa podemos hacer, sin olvidar que nos comprometimos políticamente a conservar estos paisajes?» (personal técnico del Parque Natural, entrevista \# 12). El personal del Parque muestra mucha preocupación sobre cómo gestionar desde esta figura de protección la tendencia al fuego de sus ecosistemas, teniendo en cuenta la predisposición de la zona a las tormentas con rayos, pero también la afluencia de visitantes. Afirman que "hablar de los incendios forestales como alteraciones en las áreas protegidas parece estar vetado", sin embargo, en el Parque sólo se realizó una quema prescrita (en 2002) y existen dudas sobre si deben ser diferentes las formas de gestión de los incendios según sus causas (antrópico versus naturales). Por otra parte, afirmaciones tales como « $i$ Tenemos que transformar el ecosistema en un palo con unas hojas para que las personas visitantes puedan disfrutar de su paseo o los bomberos puedan trabajar mejor?» o "La compatibilización de la conservación de la biodiversidad con las actividades humanas no es imposible, pero es difícil y complicada» sitúa a menudo al personal del Parque en una visión dicotómica entre naturaleza y sociedad, por tanto, el paisaje deseado se dibuja con elementos de una fantasía verde y «sin gente» ( $n^{\circ} 5$, figura $2 b$ ). 
Sin embargo, contextualizando las fantasías verdes, se percibe cómo en ellas no sólo está el deseo de protección, sino tambien una respuesta reactiva a cómo se distribuyen los usos del suelo en la zona. El personal del parque considera que «las actividades primarias tienden a desaparecer y, por lo tanto, se incluyen en las áreas protegidas» (personal del Parque Natural, entrevista \# 12). Aparece una "necesidad de refugio» frente a una ordenación terrirorial que propone simultáneamente zonas de conservación y un "paisaje generador de energía» (Zografos y Martínez-Alier, 2009), pero que mantiene la percepción de una «degradación deliberada del territorio» (activista de Plataforma en Defensa de la Terra Alta, entrevista \# 24).

\section{Consideraciones finales}

El incendio forestal de Orta, a través de su candencia puntual, revela información muy valiosa sobre dos aspectos esenciales de los SSE catalanes (y mediterráneos): los bosques y los incendios forestales. Con una analogía a lo que Jung (1964) llama el «arquetipo de la sombra» — aquello negativo que se manifiesta por mucho que lo intentemos reprimir - (parte de) nuestras sociedades rechazan el fuego como ciclo e intentan reprimir los incendios, a pesar de que culturalmente los refuerzan y magnifican sus impactos. Así como Davis (1998) explica que, durante los incendios forestales de Malibú, la diferencia de clase intrínseca a la formación urbana se expresa con claridad, el incendio de Orta, su desarrollo y análisis público expresan cómo están organizados los SSE. Como hemos visto durante el desarrollo de este artículo, tanto la gestión forestal como los incendios son usados a menudo como «universales» (Tsing, 2005) o significantes «flotantes» que ideologías diferentes — y por tanto políticas forestales y de ordenación territorial muy distintas - intentan «hegemonizar, para así fijar su significado mediante la articulación en su propia cadena de significantes» (Žižek, 1989, en Stavrakakis, 1997).

La desgraciada muerte de los cinco bomberos acaparó la atención de una forma evidente, pero el análisis político y la energía dedicada al conocimiento de los detalles del incendio parecen no haber servido para indagar en las causas estructurales "más allá del humo». Se perdió así la oportunidad de reflexionar específicamente acerca de las fricciones latentes - aquellas que nos hablan de qué tipo de SSE construimos mediante diferentes decisiones políticas. Sin embargo, el incipiente darse cuenta de que «el bosque regenera [pero] los bomberos nunca volverán» (varias personas entrevistadas) puede ayudar a construir nuevas condiciones de seguridad y a revaluar cómo de valiosos son los bosques que el sistema económico actual produce y cómo aceptar los límites de la capacidad de extinción.

Más allá de este humo relacionado con la primera de las fricciones identificadas en este trabajo, las otras dos fricciones que aparecen en el escenario candente de Orta son, simultáneamente, conflictos potenciales y oportunidades. Puesto que el mantenimiento del conocimiento local implicaría «volver a poner el manejo de la tierra a nivel local» (bombero del GRAF, entrevista 
\# 15), el ámbito sociopolítico debería ser reconfigurado para que viejas dicotomías (centro-periferia, sociedad-naturaleza, fuego bueno-fuego malo) no se reprodujesen (Saurí y Boada, 2006).

Por último, este trabajo muestra cómo todos los paisajes deseados pueden constituir una fantasía, tanto la fantasía verde como la ruralidad idealizada como el control de riesgos - aunque en la actualidad esta última parece adaptarse mejor a los mensajes dominantes de poder e invulnerabilidad de lo humano frente a lo natural. En todo caso, las diferentes formas de vivir un mismo paisaje incendiado expresan distintos tipos de compromiso ético con el paisaje (Cortina, 2011). Puesto que transformar la situación actual de los sistemas forestales con masas en continuo crecimiento no es ni será fácil ni instantáneo, los diálogos, los debates, las sinergias y los conflictos entre los discursos, los conocimientos y los intereses deberían comenzar a hacerse políticamente visibles tan pronto como sea posible.

\section{Agradecimientos}

Los autores agradecemos la colaboración prestada por todas las personas entrevistadas y a M. Borrós y C. Hidalgo por su ayuda en la elaboración de mapas y de diseño, respectivamente. Así mismo, agradecemos también los comentarios de los revisores.

\section{Referencias bibliográficas}

Adger, W. Neil (2000). «Social and ecological resilience: are they related?». Progress in Human Geography, 24 (3), 347-364.

Adger, W. Neil; Hughes, Terry P.; Folke, Carl; Carpenter, Stephen R. y RockSTRÖM, Johan (2005). «Social-Ecological Resilience to Coastal Disasters». Science, 309 (5737), 1036-1039.

Altieri, Miguel Á. (2002). «Agroecology: The Science of Natural Resource Management for Poor Farmers in Marginal Environments». Agriculture, Ecosystems \& Environment, 193 (1-3), 1-24.

BADIA, Anna; SAURí, David; CerdÁn, Rufí y LluRdÉs, Joan-Carles (2002). «Causality and Management of Forest Fires in Mediterranean Environments: An Example from Catalonia». Global Environmental Change Part B: Environmental Hazards, 4 (1), 23-32.

Badia, Anna; Estany, Gemma; Otero, Iago y BoAdA, Martí (2010). «Estudio del crecimiento urbano disperso y los cambios en el paisaje en Matadepera (Región Metropolitana de Barcelona)». Boletín de la Asociación de Geógrafos Españoles, 54, 301-321.

BAYONA, Jordi y GiL, Fernando (2010). «Migraciones de españoles y extranjeros en las áreas rurales catalanas (1996-2006): ¿Fin de la despoblación o nuevo modelo territorial?». Boletín de la Asociación de Geógrafos Españoles, 53, 219-237.

«Beseit, Parque Natural». La Vanguardia [en línea], 8 de marzo de 1998. <http:// hemeroteca.lavanguardia.es/>.

BRYMAN, Alan (2008). Social research methods. Oxford; Nueva York: Oxford University Press. 
CARbÓ, Salvador (2007). Guia d'Horta de Sant Joan. Diputació de Tarragona (Els Llibres de la Medusa).

Carroll, Mathew S.; Cohn, Patricia J.; Seesholtz, David N. y Higgins, Lorie L. (2005). «Fire as a Galvanizing and Fragmenting Influence on Communities: The Case of the Rodeo-Chediski Fire». Society \& Natural Resources: An International Journal, 18 (4), 301-320.

Castellnou, Marc; Nebot, Edgar y Miralles, Marta (2007). El papel del fuego en la gestión del paisaje [en línea]. <http://www.fire.uni-freiburg.de/sevilla2007/contributions/doc/SESIONES_TEMATICAS/ST1/Castellnou_et_al_2_SPAIN_Cat. pdf> [Consulta: 27 marzo 2010].

CASTELlÓ, Joan I. (2009). «Incendios forestales. Estado de la cuestión y retos de futuro». En: DipUtACIÓ DE BARCELONA. La prevención de los incendios forestales en la provincia de Barcelona. Àrea de la Presidència. Direcció de Comunicació.

COLlANTES, Fernando (2001). «La montaña española en el desarrollo capitalista, 18601991. Perifericación Segura, Difusión Condicionada». Ager: Revista de Estudios sobre Despoblación y Desarrollo Rural, 1, 9-46.

Cortina, Albert (2011). «Landscape Ethics: A moral commitment to responsible regional management». Ramon Llull Journal of Applied Ethics, 1, 163-78.

CostA, Xavier (2002). "Festive Traditions in Modernity: The Public Sphere of the Festival of the Fallasin Valencia (Spain)». The Sociological Review, 50 (4), 482-504.

CREAF (CENTRE de ReCERCA ECOlÒgiCa i Aplicacions Forestals) (2005). Inventari ecològic i forestal de Catalunya [en línea]. <http://www.creaf.uab.es/iefc/> [Consulta: 15 mayo 2010].

DAVIS, Mike (1998). Ecology of fear: Los Angeles and the imagination of disaster. Nueva York: Metropolitan Books.

Díaz-Delgado, Ricardo; Lloret, Francisco; Pons, Xavier y Terradas, Jaume (2002). «Satellite Evidence of Decreasing Resilience in Mediterranean Plant Communities After Recurrent Wildfires». Ecology, 83, 2293-2303.

ESPINET, Dolors (2010). La veritat crema. Barcelona: Pagès.

Fustel De Coulanges, Numa Dionisio (1987). La ciudad antigua. Barcelona: Iberia.

GEPEC (2007). La Fiscalia de Medi Ambient de Tarragona exculpa Interior de la responsabilitat sobre les causes de l'incendi de Vandellò [en línea]. <http://www.gepec. org/modules.php?op=modload $\&$ name $=$ News $\&$ file $=$ article $\&$ sid $=702 \&$ mode $=$ thre ad\&order $=0 \&$ thold $=0>$ [Consulta: 3 junio 2010].

- (2010). Enfront la crisi forestal i econòmica, aclarides selectives [en línia]. <http:// www.gepec.org/ftp/aclarides.pdf> [Consulta: 3 junio 2010].

Generalitat de CATAlunya (2011). Pla Infocat [en línia]. <http://www.gencat.cat/> [Consulta: 3 diciembre 2011].

Gómez-Baggethun, Erik; Mingorría, Sara; Reyes-García, Victoria; Calvet, Laura y MonTES, Carlos (2010). «Traditional Ecological Knowledge Trends in the Transition to a Market Economy: Empirical Study in the Doñana Natural Areas». Conservation Biology, 24 (3), 721-729.

GonZÁleZ, Jose A. y BuXÓ, María Jesús (eds.) (1997). El fuego, mitos, ritos y realidades: Coloquio Internacional, Granada, 1-3 de febrero de 1995. Granada: Diputación Provincial de Granada.

González, José R. y Pukkala, Timo (2007). "Characterization of Forest Fires in Catalonia (North-East Spain)». European Journal of Forest Research, 126 (3), 421-429. 
GREENPEACE (2007). El perfil de los que queman el bosque en España. <http://www. greenpeace.org/espana/Global/espana/report/bosques/informe-el-perfil-del-incen di.pdf> [Consulta: 21 junio 2010].

- (2009). El futuro en llamas. Cambio climático y evolución de los incendios forestales en España. <http://www.greenpeace.org/espana/Global/espana/report/bos ques/090813-02.pdf $>$. [Consulta: 21 junio 2010].

IDESCAT (2010). Base de datos de municipios [en línea]. <http://www.idescat.cat/> [Consulta: 10 diciembre 2011].

JUNG, Carl (1964). El hombre y sus simbolos. Barcelona: Paidós.

KARAMICHAS, John (2007). "The Impact of the Summer 2007 Forest Fires in Greece: Recent Environmental Mobilizations, Cyber-Activism and Electoral Performance». South European Society and Politics, 12 (4), 521-533.

KePE, Thembela (2005). "Grasslands Ablaze: Vegetation Burning by Rural People in Pondoland, South Africa». South African Geographical Journal, 87 (1), 10-17.

KuHLKEN, Robert (1999). "Settin' the Woods on Fire: Rural Incendiarism as Protest». Geographical Review, 89 (3), 343-363.

Kull, Christian A. (2004). Isle of fire: the political ecology of landscape burning in Madagascar. Chicago y Londres: The University of Chicago Press.

Kumagai, Yoshitaka; EdWARdS, John y Carroll, Matthew S (2006). "Why are Natural Disasters Not "natural" for Victims?». Environmental Impact Assessment Review, 26 (1), 106-119.

«La mayoría de catalanes pide dimisiones por el incendio de Horta». La Vanguardia [en línea], 12 de marzo de 2010. <http://www.lavanguardia.es/politica/ noticias/20100312/53897519251/la-mayoria-de-catalanes-pide-dimisiones-porel-incendio-de-horta-partido-popular-ciu-icv-psc-institu.html> [Consulta: 3 diciembre 2011].

Larrañaga, Asier; Galán, Moisés y Pellisa, Oriol (2005). Discusión sobre el análisis de costos de las quemas prescritas en los ámbitos de pre-extinción y gestión forestal: Valoración de 6 años de experiencia en Cataluña [en línea]. <http://www.ctfc.es/ confeinfor/articles/PAPER\%20LARRAÑAGA.pdf> [Consulta: 10 marzo 2010].

LAUK, Christian y ERB, Karl-Heinz (2009). "Biomass consumed in anthropogenic vegetation fires: global patterns and processes». Ecological Economics, 69 (2), 328-334.

LEWIS, Henry T. (1989). «Ecological and technological knowledge of fire: aborigines versus park rangers in Northern Australia». American Anthropologist, 91 (4), 940-961.

MartíneZ-Alier, Joan (2009). El ecologismo de los pobres: Conflictos ambientales y lenguajes de valoración. Barcelona: Icaria.

Minguell, Jaume y ÀNGEL, Joan C. (2009). «El bosc a Catalunya: Un problema sectorial i estructural». En: DIPUTACIÓ DE BARCELONA. La prevención de los incendios forestales en la provincia de Barcelona. Barcelona: Àrea de la Presidència. Direcció de Comunicació.

Ministerio de Medio Ambiente (2006). Los incendios forestales en España [en línea]. <http://www.mma.es/secciones/biodiversidad/defensa_incendios/estadisticas_ incendios/pdf/decenio_1996_2005.pdf> [Consulta: 30 abril 2010].

MinniCH, Richard A. (1983). «Fire Mosaics in Southern California and Northern Baja California». Science, 219 (4590), 1287-1294.

Miralles, Ferran (2005). Mil anys pels camins de l'herba: El llegat d'un món que s'acaba. Barcelona: Edafós. 
Molinero, Fernando; García, Alipio; Santos, Cayetano; Baraja, Eugenio y Guerra, Juan C. (2008). "Percepción local de los incendios forestales y sus motivaciones en Castilla y León». Ería: Revista Cuatrimestral de Geografía, 76, 213-229.

Moreno, José M. (2007). "Cambio global e incendios forestales: una visión desde España». 4a Conferencia Internacional sobre Incendios Forestales. Sevilla 2007 [en línea]. <http://www.fire.uni-freiburg.de/sevilla-2007/contributions/doc/cd/MA GISTRALES/Moreno_JM_magistral.pdf> [Consulta: 30 abril 2010].

Mouffe, Chantal (2007). En torno a lo político. México: Fondo de Cultura Económica.

NAveH, Zev (1975). "The evolutionary significance of fire in the Mediterranean Region». Vegetatio, 29 (3), 199-208.

NoGUÉ, Joan y ViCENTE, Joan (2004). «Landscape and national identity in Catalonia». Political Geography, 23 (2), 113-132.

OTERO, Iago (2010). The rural-urban socioecological transformation of Mediterranean mountain areas under global change. Local studies in Ozinelles and Matadepera (Barcelona Metropolitan Region). Barcelona: Institut de Ciència i Tecnologia Ambientals, Universitat Autònoma de Barcelona. Tesis doctoral dirigida por Martí Boada.

Outeiro, Luis; AsPeró, Francesc; MAtAix, Jorge y ÚbedA, Xavier (2007). «Foc com a causant de canvis en les propietats del sòl: Incendis forestals i cremes prescrites». Treballs de la Societat Catalana de Geografia, 63, 229-252.

PAUSAS, Juli G. y LlORET, Francisco (2007). «Spatial and temporal patterns of plant functional types under simulated fire regimes». International Journal of Wildland Fire, 16 (4), 484-492.

Pausas, Juli; Llovet, Joan; Rodrigo, Anselm y Vallejo, Ramón (2008). «Are wildfires a disaster in the Mediterranean basin?». International Journal of Wildland Fire, 17, 713-723.

PEET, Richard y WATTS, Michael (2004). Liberation ecologies: environment, development, social movements. Londres, Nueva York: Routledge.

PIÑOL, Josep; TerradAS, Jaume y LlORET, Francisco (1998). "Climate warming, wildfire hazard, and wildfire occurrence in coastal eastern Spain». Climatic Change, 38 (3), 345-357.

Piñol, Josep; BeVEn, Keith y VIEgas, Domingos Xavier (2005). «Modelling the effect of fire-exclusion and prescribed fire on wildfire size in Mediterranean ecosystems». Ecological Modelling, 183 (4), 397-409.

PlanA, Eduard; DOMíngueZ, Glòria y SANGRÀ, Gerard (2002). «La problemàtica dels grans incendis forestals com a causa-efecte del desequilibri territorial al món rural. Aprenent de l'experiència de 1998». Enginyeria i Sostenibilitat. I Congrés d'Enginyers en Llengua Catalana, 2, 49-67.

Plana, Eduard; Cerdan, Rufí y Castellnou, Marc (2005). Developing firebreaks [en línea]. <http://www.floresta.ufpr.br/firelab/artigos/artigo106.pdf> [Consulta: 10 marzo 2010].

PynE, Stephen J. (1997). Vestal fire: an environmental history, told through the fire, of Europe and Europe's encounter with the world. Washington: University of Washington Press.

- (2001). "An exchange for all things? An inquiry into the scholarship of fire». Australian Geographical Studies, 39 (1), 1-16.

RAMOS-GorostizA, José L. (2006). «Gestión ambiental y política de conservación de la naturaleza en la España de Franco». Revista de Historia Industrial, 32 (3), 99-138. 
RobBins, Paul (2004). Political ecology: a critical introduction. Malden: Blackwell.

Rodrigo, Anselm; Retana, Javier y Pico, F. Xavier (2004). "Direct regeneration is not the only response of Mediterranean forests to large fires». Ecology, 85 (3), 716-729.

SANTOS, Xavier; Bros, Vicenç y MiÑo, Àngel (2009). «Recolonization of a burned Mediterranean area by terrestrial gastropods». Biodiversity and Conservation, 18 (12), 3153-3165.

SAURí, David y BOADA, Martí (2006). «Sostenibilidad y cultura campesina: Hacia modelos alternativos de desarrollo rural. Una propuesta desde Cataluña. Boletín de la Asociación de Geógrafos Españoles, 41, 315-328.

SEIJO, Francisco (2005). «The Politics of Fire: Spanish Forest Policy and Ritual Resistance in Galicia, Spain». Environmental Politics, 14 (3), 380-402.

- (2009a). «Fuego bueno, fuego malo: fuerzas motrices del cambio en los regímenes de incendios forestales en la península Ibérica durante el antropoceno». Cuaderno de la Sociedad Española de Ciencias Forestales, 30, 367-372.

- (2009b). «Who framed the forest fire?: State framing and peasant counter-framing of anthropogenic forest fires in Spain since 1940». Journal of Environmental Policy \& Planning, 11 (2), 103-128.

SIDDLE, David (2009). "Goats, marginality and the "Dangerous Other"». Environment and History, 15 (4), 521-536.

SLETTO, Bjørn (2008). "The knowledge that counts: institutional identities, policy science, and the conflict over fire management in the Gran Sabana, Venezuela». World Development, 36 (10), 1938-1955.

STAVRAKAKIS, Yanni (1997). «Green ideology: A discursive reading». Journal of Political Ideologies, 2 (3), 259-279.

SwYNGEDOUW, Erik (2010). «Apocalypse Forever?: Post-political Populism and the Spectre of Climate Change». Theory, Culture \& Society, 27 (2-3), 213-232.

TÀbara, David; SAurí, David y CERDAN, Rufí (2003). «Forest fire risk management and public participation in changing socioenvironmental conditions: A case study in a Mediterranean region». Risk Analysis, 23 (2), 249-260.

TERradAs, Jaume (coord.) (1996). Ecologia del foc. Barcelona: Proa.

- (2001). Ecología de la vegetación: De la ecofisiología de las plantas a la dinámica de comunidades y paisajes. Barcelona: Omega.

Tsing, Anna. L. (2005). Friction: an etnography of global connection. Princeton: Princeton University Press.

VILAR, Pierre (dir.) (2003). Història de Catalunya. Barcelona: Edicions 62.

WINTER, Greg y FrIED, Jeremy. S. (2000). «Homeowner perspectives on fire hazard, responsibility, and management strategies at the wildland-urban interface». Society \& Natural Resources: An International Journal, 13 (1), 33-49.

Xanthopoulos, Gavriil (2004). «Who should be responsible for forest fires?: Lessons from the Greek experience». Proceedings of the Second International Symposium on Fire Economics, Planning, and Policy: A Global View [en línea]. <www.fs.fed.us/ psw/publications/documents/psw_gtr208en/psw_gtr208en_189-202_xanthopoulos.pdf> [Consulta: 12 enero 2010].

ŽIŽEK, Slavoj (1991). Looking awry: an introduction to Jacques Lacan through popular culture. Massachusetts: MIT Press.

Zografos, Christos y MARTíneZ-Alier, Joan (2009). «The politics of landscape value: A case study of wind farm conflict in rural Catalonia». Environment and Planning A, 41 (7), 1726-1744. 